\title{
Rice paddy environment and productivity under changing climate
}

\author{
Akira MiYATA $^{\mathrm{a}, \dagger}$ \\ ( ${ }^{a}$ Institute for Agro-Environmental Sciences, NARO, 3-1-3 Kannondai, Tsukuba, Ibaraki 305-8604, Japan )
}

Rice fields are found commonly in monsoon Asia and are distributed widely in the world. Rice fields are generally flooded during the growing season, and this provides a unique agricultural ecosystem that consists of soil, water, plants and the atmosphere. The first paper published in Journal of Agricultural Meteorology was titled "Micrometeorological studies on the rice field" (Suzuki et al., 1943). Since then, a variety of agro-meteorological studies on rice fields have been made to understand characteristics of rice fields in comparison with other non-flooded croplands. As early as the 1950s and the 1960s, micrometeorological studies on water temperature, turbulence above and within rice canopy, heat and water balance and leaf/ canopy photosynthesis were made (e.g. Uchijima, 1976), and those fundamental studies were synthesized into a systematic rice canopy model, which was later utilized in northern Japan to reduce cool summer damage of rice. In the late 1990s, new experimental platforms such as FACE (Free-Air $\mathrm{CO}_{2}$ Enrichment) and tower flux monitoring sites were made in rice fields to cope with climate change. Those platforms are utilized for various studies such as micrometeorology of rice canopy under elevated $\mathrm{CO}_{2}$ conditions, long-term changes of carbon and water exchange and methane emission. To survey recent micrometeorological and biogeochemical studies in rice fields and to discuss direction of further studies, a small meeting sponsored by JapanFlux was held in Okayama, Japan, March 2016 as an organized session of the Annual Meeting of the Society of Agricultural Meteorology of Japan. Based on the meeting, this special issue "Rice paddy environment and productivity under changing climate” was planned. Although this special issue is a small collection of agro-meteorological studies on rice fields, it covers a wide range of topics from phenological modelling to morphological sensing and a variety of approaches from laboratory experiment to satellite remote sensing. Five of the seven articles are related to Mase paddy flux site (Fig. 1). We hope this special issue will help readers to realize that various agro-meteorological studies are going on in rice fields, as in other croplands, to cope with climate change. Publication of this special issue owes much to Dr. Keisuke Ono.

\section{References}

Suzuki S, Ohmori H, Okanoue M, 1943: Micrometeorological studies on the rice field. Journal of Agricultural Meteorology 1, 1-7. (in Japanese)

Uchijima Z, 1976: Maize and rice. In Vegetation and the Atmosphere Volume 2 Case Studies (ed. by Monteith JL). Academic Press, London, pp.33-64.

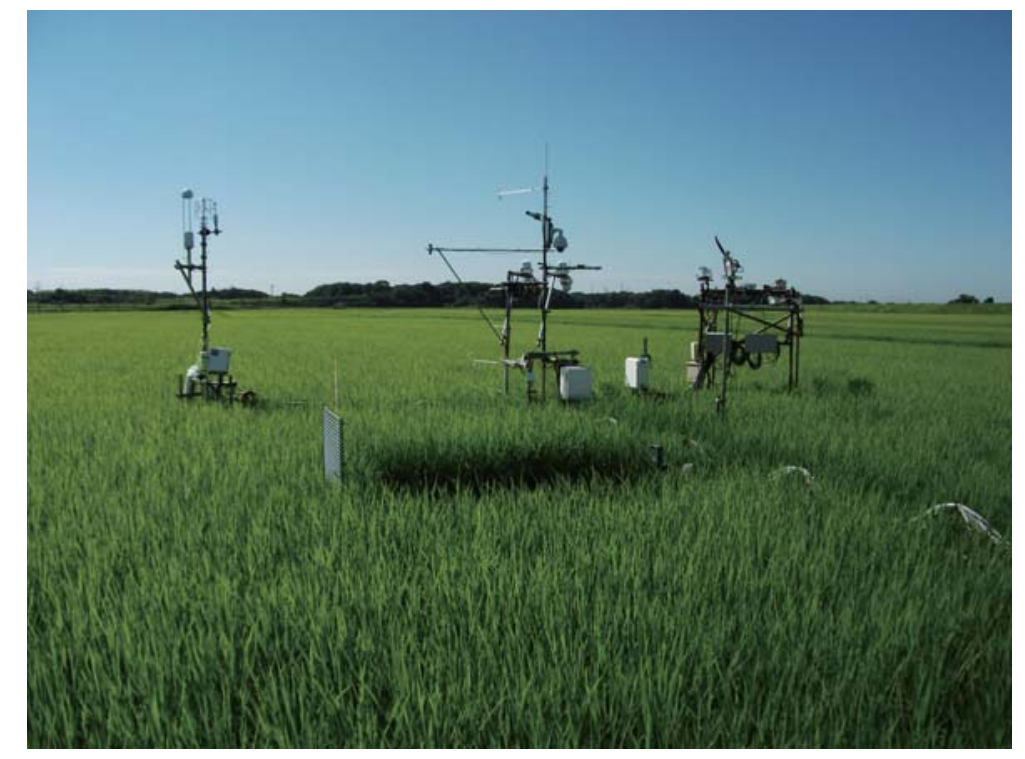

Fig. 1. Mase paddy flux site, Japan.

\footnotetext{
${ }^{\dagger}$ Corresponding Author: amiyat@affrc.go.jp
}

DOI: 10.2480/agrmet.D-17-00101 